DOI: $10.14451 / 1.193 .110$

\title{
ПУТИ ПОВЫШЕНИЯ КАЧЕСТВА ЖИЗНИ НАСЕЛЕНИЯ
}

\author{
(c) 2020 Рагозина Анастасия Юрьевна \\ соискатель \\ Уральский государственный экономический университет, Россия, Свердловская область, Серов \\ E-mail: Anastasia453@yandex.ru
}

В статье рассмотрены пути повышения качества жизни населения путем реализации национальных проектов, таких как «Образование», «Здоровье», «Жилье». Приведены главные направления работы в Программе социально-экономического развития, главной задачей которых является повышение качества жизни населения. Рассмотрены основные направления деятельности Министерства по повышению качества жизни при взаимной работе с иными федеральными органами исполнительной власти, органами исполнительной власти субъектов РФ и органами местного самоуправления и предприятиями. Приведенные автором направления программы социальноэкономического развития Правительства РФ направлены на повышение качества жизни населения, сокращение бедности в целом по России, обеспечение достойных условий для жизни людей и развития социального государства.

Ключевые слова: качество жизни, национальный проект, пути повышения, здоровье, образование, жилье.

\section{Введение}

Существующая система модернизации экономики способствует формированию новых социально-экономических условий, главным критерием экономического развития страны является высокое качество жизни населения.

Сегодняшнее состояние качества жизни населения нуждается в существенной корректировке, поскольку деструктивные последствия проводимых в начале 90-х годов преобразований содействовали не только существенной дифференциации населения, снижению качества жизни значительной доли жителей страны, но и появлению такой категории, как бедность. Проблема осложняется еще и тем, что в последние годы социальная и территориальная дифференциация населения усиливается. Для своевременного выявления перечисленных проблем требуется эффективная система оценки качества жизни и на основе этого должны разрабатываться пути его повышения.

Целью исследования является определение путей повышения качества жизни населения.

\section{Материал и методы исследования.}

Материалами исследования явились научные теории и концепции российских и зарубежных ученых в области качества жизни. В качестве методов исследования применялись анализ, обобщение, сравнение, экспертных оценок.
Результаты исследования и их обсуждение.

Главной задачей государственной политики является повышение качества жизни граждан. Данная цель осуществляется путем реализации национальных проектов. В данное время первостепенными являются три проекта: качественное образование, здравоохранение, доступное и комфортное жилье.

Данные направления касаются любого человека, определяют качество жизни и генерируют здоровую и образованную нацию. Жители именно в этих направлениях ожидают активной роли государства.

В настоящее время состояние здоровья обладает низким уровнем рождаемости (10 случаев на 1000 населения), высоким уровнем смертности (15 случаев на 1000 населения). Смертность людей в трудоспособном возрасте в нашей стране является одной их главных проблем. Каждый год регистрируется около 200 миллионов заболеваний различной этимологии [11]. При этом показатели здоровья отрицательно сказываются на продолжительности жизни.

Усовершенствование профилактики и первичной медицинской помощи является приоритетным, потому что в прошлом здравоохранение было ориентировано на оказание стационарной помощи и это привело недофинансированию первичной медицинской помощи. Поэтому необходимо направить средства 


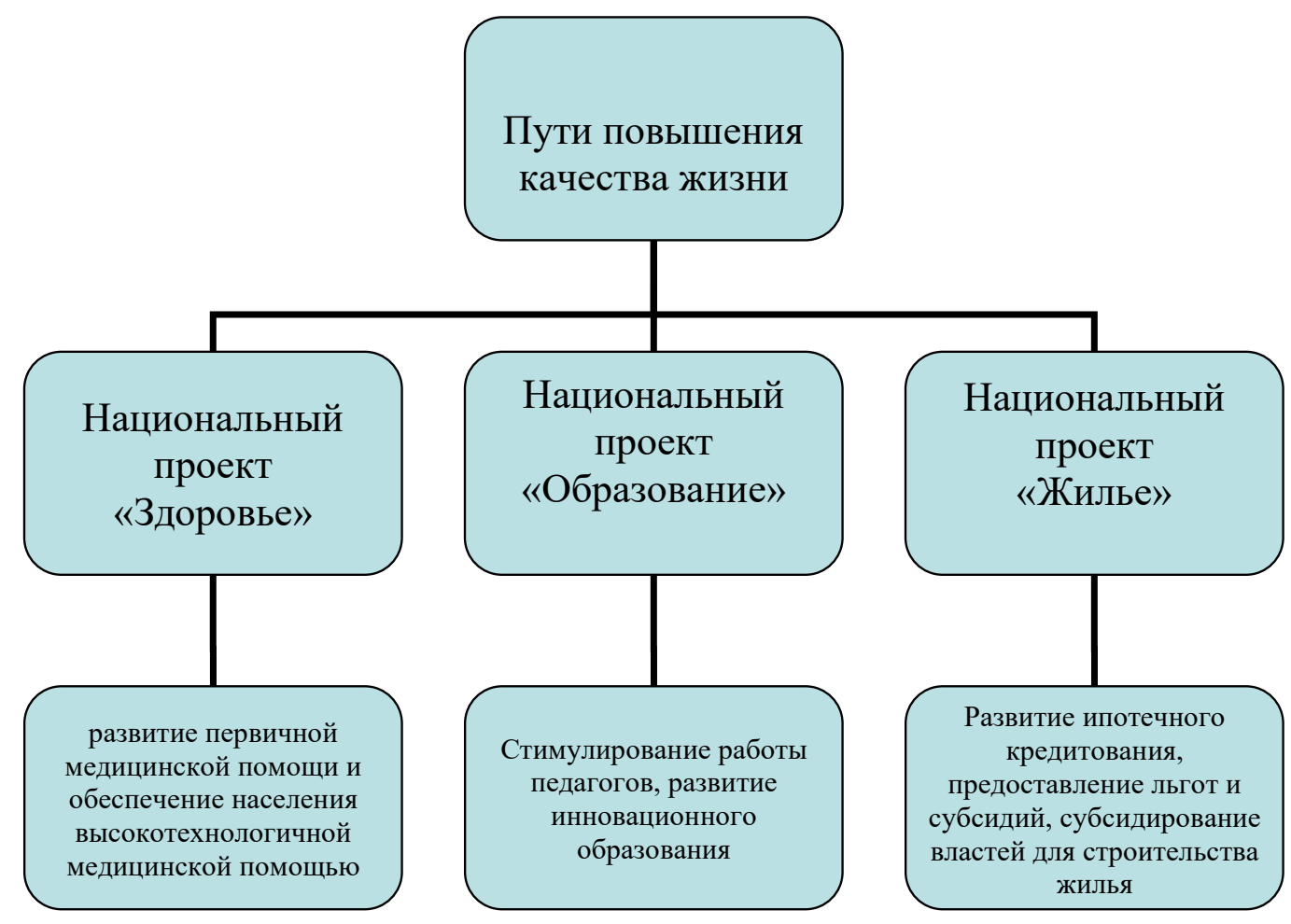

Puc. 1. Пути повышения качества жизни.

Источник: составлено автором.

на развитие диагностики, что позволит создать систему со сниженными затратами на лечение, поскольку болезнь легче предупредить, чем ее лечить. Не все граждане страны могут получить дорогостоящую медицинскую помощь, поэтому необходимо сделать ее доступнее.

Демографическая политика является одним из ключевых аспектов проекта «Здоровье», которая осуществляется через системы различных выплат.

В основе проекта «Образование» лежит проведение профессионального конкурса среди учителей, где будут выявлены те педагоги, которые достойны поощрения. Так же для выделения помощи от государства будут выявляться общеобразовательные учреждения, которые внедряют инновационные программы. Средства будут направляться в форме субсидий из разных уровней бюджета. Данная поддержка направлена для приобретения лабораторного оборудования, программного и методического обеспечения, улучшения материально-технической базы и повышения квалификации педагогических работников.

Инновационное образование - это образование, которое позволяет овладеть базовыми компетенциями для самостоятельного получе- ния знаний. Данное образование тесно взаимосвязано с практикой. Оно предполагает обучение новым знаниям при интеграции науки, учебного процесса и производства.

Большие объемы и малые сроки возврата кредита является на данный момент главной проблемой ипотечного кредитования. Для того, чтобы выдавать долгосрочные кредиты (более 15 лет) у банков не хватает собственных ресурсов. Данная проблема в мире решается путем выпуска банками ипотечных облигаций, которые позволяют привлечь средства инвесторов. Чем больше банк привлечет денег, тем больше он выдаст кредитов под более низкие проценты. Так же существует другой способ решения проблемы - рефинансирование ипотечных кредитов. Правительством РФ оператор вторичного рынка, которые осуществляет рефинансирование данных кредитов в больших объемах и благодаря этому есть возможность развивать ипотеку.

Главными направлениями работы в Программе социально-экономического развития Правительства РФ будут:

- на основе повышения рождаемости и сокращения смертности решение демографических проблем; 
- в бюджетной сфере повышение уровня и эффективности оплаты труда;

- повышение материального уровня пенсионеров;

- оказание материальной поддержки семьям, которые находятся за чертой бедности

- профилактика сиротства, предупреждение семейного неблагополучия и усовершенствование форм устройства детей, оставшихся без попечения родителей;

- осуществление реабилитации детей с ограниченными возможностями и их адаптация в обществе;

- развитие благотворительности;

- осуществление мер направленных на совершенствование квалификации граждан, ищущих работу;

- повышение территориальной мобильности населения;

- привлечение высококвалифицированных трудовых ресурсов.

Все мероприятия, проводимые по данным направлениям содействовать решению главной задачи - повышение уровня и качества жизни населения [3,5].

По данным направлениям вся деятельность осуществляется Министерство при взаимной работе с иными федеральными органами исполнительной власти, органами исполнительной власти субъектов РФ и органами местного самоуправления и предприятиями [6]. К основным направления относятся:

1. Улучшение демографической ситуации, а так же улучшение ситуации семей, имеющих детей и находящихся в трудной жизненной ситуации.

Целью является снижение бедности и неравенства населения по доходам, повышение благосостояния.

Для достижения поставленной цели необходимо слаженное взаимодействие федеральных органов исполнительной власти и органов исполнительной власти субъектов РФ.

Данное направление связано с ситуацией на рынке труда и занятостью населения.

2. Доступность и повышения качества медицинской помощи, оснащение лекарствами, в первую очередь малообеспеченные слои населения.

Целью является рост качества и доступности медицинской помощи, обеспечение лекарствами для малоимущих слоев, обеспечение санитарно-эпидемиологического благополучия.

3. Повышение эффективности системы социального обслуживания и социальной защиты.

Цель - улучшение системы социального обслуживания и социальной защиты, особенно пожилых граждан и инвалидов.

4. Поддержка занятости населения, гарантия прав граждан в области труда.

Целью является поддержка продуктивной занятости населения и гарантия прав граждан в области труда.

Политика государства в области занятости населения тесно связана с решением проблем социально-экономического развития и ориентирована на создание экономических, институциональных и правовых положений для повышения эффективности труда рабочих, обеспечение учета интересов и гарантий работников и работодателей.

В области занятости политика государства направлена на:

- поддержка в осуществлении прав граждан на достойный труд по роду своей деятельности и профессии и на свободное распоряжение своими способностями к труду;

- гарантия реализации права граждан на защиту от безработицы;

- профилактика и предотвращение нарушений прав трудящихся, в том числе дискриминации труда, так же гарантия соблюдения прав в области охраны труда;

- поддержка обеспечению работодателей рабочей силой в нужном количестве и требуемой квалификации.

\section{Заключение}

Основные направления повышения качества жизни населения страны сводятся к следующим:

1. Улучшение демографической ситуации, а так же улучшение ситуации семей, имеющих детей и находящихся в трудной жизненной ситуации.

2. Снижение бедности и неравенства населения по денежным доходам, повышение благосостояния населения.

3. Доступность и повышения качества медицинской помощи, оснащение лекарствами, в первую очередь малообеспеченные слои населения.

4. Повышение эффективности системы социального обслуживания и социальной защиты.

5. Поддержка занятости населения, гарантия прав граждан в области труда. 


\section{Вывод}

Приведенные автором направления программы социально-экономического развития Правительства РФ направлены на повышение качества жизни населения, сокращение бедности в целом по России, обеспечение достойных условий для жизни людей и развития социального государства.

\section{Библиографический список}

1. Бобков В.Н. О программе повышения уровня и качества жизни// Проблемы теории и практики управления - 1999.- № 6.- С.92-97.

2. Богомолова Т. Ю. Бедность в современной России: измерение и анализ // Экономическая наука современной России. 2005.№ 1 С. 93-106.

3. Давыдова Е. В., Давыдов А. А. Измерения качества жизни [Текст]. М.:1993. 52с.

4. Дымов. Индекс развития человеческого потенциала - что это такое?// Пропаганда. - 2008 - [Электронный ресурс] // Режим доступа: http://propaganda-journal.net/273.html

5. Загородникова Т. Об уровне жизни населения // Вопросы статистики - 1998. -№ 6.

6. Институт демографических исследований [Электронный ресурс]/У Режим доступа: http://www.demographia. $\mathrm{ru} /$

7. Качество жизни: проблемы и перспективы XXI века / кол. авт.; под общ. и науч. ред. Г. В. Астратовой. - Екатеринбург: УГЛТУ, 2013.- 532 с.

8. Косьмина, E. А. Качество жизни и его основные детерминанты / Е. А. Косьмина // Вестник экономической интеграции. - 2013. - № 1-2.- С. 178-192.

9. Леочи, П. Качество жизни и устойчивое развитие / П. Леочи // Экономические науки. - 2012.- № 5.- С. 41-45.

10. Нестерова, О.Ю. Качество жизни как фактор социального развития / О.Ю.Нестерова // Актуальные вопросы современной науки и образования: материалы I Междунар. науч.-практ. конф. - М.: Перо, 2016.- C. 74-77.

11. Сайт Федеральной Службы Государственной Статистики [Электронный ресурс] // Режим доступа: http:// www.gks.ru//.

12. Стойчева, С.С. Качество жизни населения. Технологии повышения качества жизни / С.С.Стойчева, Д.Р.Крылов // XXVI Ершовские чтения: сб. науч. ст. с междунар. участием.- Ишим: Ишимский пед. ин-т им. П. П. Ершова, 2016.- С. 31-34. 